\title{
Fixed point theorems on $b$-metric spaces for weak contractions with auxiliary functions
}

\author{
Arslan Hojat Ansari ${ }^{1}$, Sumit Chandok ${ }^{2}$ and Cristiana lonescu ${ }^{3 *}$
}

\author{
"Correspondence: \\ cristianaionescu58@yahoo.com \\ ${ }^{3}$ Department of Mathematics and \\ Informatics, University Politehnica of \\ Bucharest, Bucharest, 060042, \\ Romania \\ Full list of author information is \\ available at the end of the article
}

\begin{abstract}
In this paper, we obtain some fixed point results for generalized weakly contractive mappings with some auxiliary functions in the framework of $b$-metric spaces. The proved results generalize and extend the corresponding well-known results of the literature. Some examples are also provided in order to show that these results are more general than the well-known results existing in literature.
\end{abstract}

MSC: Primary $47 \mathrm{H} 10$; secondary $54 \mathrm{H} 25$

Keywords: fixed point; $b$-metric space; sequentially convergent mappings

\section{Introduction}

The Banach contraction principle [1] is a basic result on fixed points for contractive-type mappings. So far, there have been a lot of fixed point results dealing with mappings satisfying diverse types of contractive inequalities. Various researchers have worked on different types of inequalities having continuity on mapping or not on different abstract spaces viz. metric spaces [2-4], convex metric spaces [5], ordered metric spaces [6], cone metric spaces $[7,8]$, generalized metric spaces $[9,10], b$-metric spaces [11-15] and many more (see [16-20] and references cited therein).

In 1993, Czerwik [12] introduced the $b$-metric spaces. These form a nontrivial generalization of metric spaces and several fixed point results for single and multivalued mappings in such spaces have been obtained since then (see $[11,14,15,21]$ and references cited therein).

Let $(X, d)$ be a metric space and $T: X \rightarrow X$. A mapping $T$ is said to be a $K$-contraction [4] if there exists $\alpha \in\left(0, \frac{1}{2}\right)$ such that for all $x, y \in X$ the following inequality holds:

$$
d(T x, T y) \leq \alpha(d(x, T x)+d(y, T y))
$$

In 1968, Kannan [4] proved that if $(X, d)$ is a complete metric space, then every $K$ contraction on $X$ has a unique fixed point.

In 1972, Chatterjea [2] established a fixed point theorem for $C$-contractions mappings, that is, a mapping $T$ is said to be a $C$-contraction if there exists $\alpha \in\left(0, \frac{1}{2}\right)$ such that for all $x, y \in X$ the following inequality holds:

$$
d(T x, T y) \leq \alpha(d(x, T y)+d(y, T x)) .
$$


Various researchers generalize and/or extend Kannan and Chatterjea type contraction mappings to obtain fixed point results in abstract spaces (see [3, 5, 7, 8, 12, 13, 22-31] and references cited therein). In this paper, we generalize and extend the Kannan and Chatterjea type contractions with some auxiliary functions to obtain some new fixed point results in the framework of $b$-metric spaces. The proved results generalize and extend the corresponding well-known results of Chandok [22-25], Choudhury [27], Filipović et al. [7], Harjani et al. [28], Moradi [29], Morales and Rojas [8], Razani and Parvaneh [30] and of Shatanawi [31].

\section{Preliminaries}

To begin with, we give some basic definitions and notations which will be used in the sequel.

Definition 2.1 ([12]) Let $X$ be a (nonempty) set and $s \geq 1$ be a given real number. A function $d: X \times X \rightarrow \mathbb{R}^{+}$is a $b$-metric if, for all $x, y, z \in X$, the following conditions are satisfied:

$\left(b_{1}\right) d(x, y)=0$ iff $x=y$,

$\left(b_{2}\right) d(x, y)=d(y, x)$,

$\left(b_{3}\right) d(x, z) \leq s[d(x, y)+d(y, z)]$.

The pair $(X, d)$ is called a $b$-metric space.

It should be noted that the class of $b$-metric spaces is effectively larger than that of metric spaces, since a $b$-metric is a metric if (and only if) $s=1$. We present an easy example to show that in general a $b$-metric need not be a metric.

Example 2.1 Let $(X, \rho)$ be a metric space, and $d(x, y)=(\rho(x, y))^{p}$, where $p \geq 1$ is a real number. Then $d$ is a $b$-metric with $s=2^{p-1}$. However, $(X, d)$ is not necessarily a metric space. For example, if $X=\mathbb{R}$ is the set of real numbers and $\rho(x, y)=|x-y|$ is the usual Euclidean metric, then $d(x, y)=(x-y)^{2}$ is a $b$-metric on $\mathbb{R}$ with $s=2$, but it is not a metric on $\mathbb{R}$.

It should also be noted that a $b$-metric might not be a continuous function (see Example 3 of [21]). Thus, while working in $b$-metric spaces, the following lemma is useful.

Lemma 2.1 ([11]) Let $(X, d)$ be a b-metric space with $s \geq 1$, and suppose that $\left\{x_{n}\right\}$ and $\left\{y_{n}\right\}$ are $b$-convergent to $x, y$, respectively. Then we have

$$
\frac{1}{s^{2}} d(x, y) \leq \liminf _{n \rightarrow \infty} d\left(x_{n}, y_{n}\right) \leq \limsup _{n \rightarrow \infty} d\left(x_{n}, y_{n}\right) \leq s^{2} d(x, y) .
$$

In particular, if $x=y$, then we have $\lim _{n \rightarrow \infty} d\left(x_{n}, y_{n}\right)=0$. Moreover, for each $z \in X$, we have

$$
\frac{1}{s} d(x, z) \leq \liminf _{n \rightarrow \infty} d\left(x_{n}, z\right) \leq \limsup _{n \rightarrow \infty} d\left(x_{n}, z\right) \leq s d(x, z) .
$$

Definition 2.2 Let $(X, d)$ be a metric space. A mapping $T: X \rightarrow X$ is said to be sequentially convergent [32] (respectively, subsequentially convergent) if, for every sequence $\left\{x_{n}\right\}$ in $X$ for which $\left\{T x_{n}\right\}$ is convergent, $\left\{x_{n}\right\}$ is also convergent (respectively, $\left\{x_{n}\right\}$ has a convergent subsequence). 


\section{Main results}

We denote by $\Psi$ the family of functions $\psi:[0, \infty) \rightarrow[0, \infty)$ such that $\psi$ is continuous, strictly increasing and $\psi^{-1}(\{0\})=0$.

Also we denote by $\Phi$ the family of functions $\varphi:[0, \infty)^{2} \rightarrow[0, \infty)$ such that $\varphi(0,0) \geq 0$, $\varphi(x, y)>0$ if $(x, y) \neq(0,0)$, and $\varphi\left(\liminf _{n \rightarrow \infty} a_{n}, \liminf _{n \rightarrow \infty} b_{n}\right) \leq \liminf _{n \rightarrow \infty} \varphi\left(a_{n}, b_{n}\right)$.

Theorem 3.1 Let $(X, d)$ be a complete $b$-metric space with parameter $s \geq 1, T, f: X \rightarrow X$ be such that, for some $\psi \in \Psi, \varphi \in \Phi$, and all $x, y \in X$,

$$
\psi(s d(T f x, T f y)) \leq \frac{\psi\left(\frac{d(T x, T f y)+d(T y, T f x)}{s+1}\right)}{1+\varphi(d(T x, T f y), d(T y, T f x))},
$$

and let $T$ be one-to-one and continuous. Then:

(1) For every $x_{0} \in X$ the sequence $\left\{T f^{n} x_{0}\right\}$ is convergent.

(2) If $T$ is subsequentially convergent then $f$ has a unique fixed point.

(3) If $T$ is sequentially convergent then, for each $x_{0} \in X$ the sequence $\left\{f^{n} x_{0}\right\}$ converges to the fixed point off.

Proof Let $x_{0} \in X$ be arbitrary. Consider the sequence $\left\{x_{n}\right\}_{n=0}^{\infty}$ given by $x_{n+1}=f x_{n}=f^{n+1} x_{0}$, for $n \geq 0$.

Step I. First, we will prove that $\lim _{n \rightarrow \infty} d\left(T x_{n}, T x_{n+1}\right)=0$.

Using (3.1), we obtain

$$
\begin{aligned}
\psi\left(s d\left(T x_{n+1}, T x_{n}\right)\right) & =\psi\left(s d\left(T f x_{n}, T f x_{n-1}\right)\right) \\
& \leq \frac{\psi\left(\frac{d\left(T x_{n}, T f x_{n-1}\right)+d\left(T x_{n-1}, T f x_{n}\right)}{s+1}\right)}{1+\varphi\left(d\left(T x_{n}, T f x_{n-1}\right), d\left(T x_{n-1}, T f x_{n}\right)\right)} \\
& =\frac{\psi\left(\frac{d\left(T x_{n}, T x_{n}\right)+d\left(x_{n-1}, T x_{n+1}\right)}{s+1}\right)}{1+\varphi\left(d\left(T x_{n}, T x_{n}\right), d\left(T x_{n-1}, T x_{n+1}\right)\right)} .
\end{aligned}
$$

Since $\varphi$ is nonnegative and $\psi$ is an increasing function and using the triangular inequality we have

$$
\begin{aligned}
\psi\left(s d\left(T x_{n+1}, T x_{n}\right)\right) & \leq \psi\left(\frac{d\left(T x_{n-1}, T x_{n+1}\right)}{s+1}\right) \\
& \leq \psi\left(\frac{s}{s+1}\left(d\left(T x_{n-1}, T x_{n}\right)+d\left(T x_{n}, T x_{n+1}\right)\right)\right) .
\end{aligned}
$$

Again, since $\psi$ is increasing, we have

$$
d\left(T x_{n+1}, T x_{n}\right) \leq \frac{1}{s+1}\left(d\left(T x_{n-1}, T x_{n}\right)+d\left(T x_{n}, T x_{n+1}\right)\right),
$$

wherefrom

$$
d\left(T x_{n+1}, T x_{n}\right) \leq \frac{1}{s} d\left(T x_{n}, T x_{n-1}\right) \leq d\left(T x_{n}, T x_{n-1}\right) .
$$

Thus, $\left\{d\left(T x_{n+1}, T x_{n}\right)\right\}$ is a decreasing sequence of nonnegative real numbers and hence it is convergent. 
Assume that $\lim _{n \rightarrow \infty} d\left(T x_{n+1}, T x_{n}\right)=r \geq 0$. From the above argument we have

$$
\begin{aligned}
s d\left(T x_{n+1}, T x_{n}\right) & \leq \frac{1}{s+1} d\left(T x_{n-1}, T x_{n+1}\right) \\
& \leq \frac{s}{s+1}\left(d\left(T x_{n-1}, T x_{n}\right)+d\left(T x_{n}, T x_{n+1}\right)\right) \\
& \leq \frac{s}{2}\left(d\left(T x_{n-1}, T x_{n}\right)+d\left(T x_{n}, T x_{n+1}\right)\right)
\end{aligned}
$$

On taking the limit $n \rightarrow \infty$, we obtain

$$
\lim _{n \rightarrow \infty} d\left(T x_{n-1}, T x_{n+1}\right)=s(s+1) r
$$

From (3.2), we have

$$
\psi\left(s d\left(T x_{n+1}, T x_{n}\right)\right) \leq \frac{\psi\left(\frac{0+d\left(T x_{n-1}, T x_{n+1}\right)}{s+1}\right)}{1+\varphi\left(0, d\left(T x_{n-1}, T x_{n+1}\right)\right)}
$$

On letting $n \rightarrow \infty$ and using the continuity of $\psi$ and the properties of $\varphi$ we get

$$
\psi(s r) \leq \frac{\psi(s r)}{1+\varphi(0, s(s+1) r)}
$$

and consequently, $\psi(s r)=0$. Hence using the properties of $\psi$, we have

$$
r=\lim _{n \rightarrow \infty} d\left(T x_{n}, T x_{n+1}\right)=0
$$

Step II. Now in next step we will show that $\left\{T x_{n}\right\}$ is a $b$-Cauchy sequence.

Suppose that $\left\{T x_{n}\right\}$ is not a $b$-Cauchy sequence. Then there exists $\varepsilon>0$ for which we can find subsequences $\left\{T x_{m_{k}}\right\}$ and $\left\{T x_{n_{k}}\right\}$ of $\left\{T x_{n}\right\}$ with $n_{k}$ is the smallest index for which $n_{k}>m_{k}>k$ such that

$$
d\left(T x_{m_{k}}, T x_{n_{k}}\right) \geq \varepsilon
$$

and

$$
d\left(T x_{m_{k}}, T x_{n_{k}-1}\right)<\varepsilon
$$

From (3.4), (3.5), and using the triangular inequality, we have

$$
\begin{aligned}
\varepsilon & \leq d\left(T x_{m_{k}}, T x_{n_{k}}\right) \leq s\left[d\left(T x_{m_{k}}, T x_{n_{k}-1}\right)+d\left(T x_{n_{k}-1}, T x_{n_{k}}\right)\right] \\
& <s \varepsilon+s d\left(T x_{n_{k}-1}, T x_{n_{k}}\right) .
\end{aligned}
$$

On letting $k \rightarrow \infty$, and using (3.3), we obtain

$$
\varepsilon \leq \limsup _{k \rightarrow \infty} d\left(T x_{m_{k}}, T x_{n_{k}}\right) \leq s \varepsilon
$$


Further, we have

$$
d\left(T x_{m_{k}}, T x_{n_{k}}\right) \leq s\left[d\left(T x_{m_{k}}, T x_{n_{k}-1}\right)+d\left(T x_{n_{k}-1}, T x_{n_{k}}\right)\right] .
$$

Now using (3.3) and (3.5), we get

$$
\frac{\varepsilon}{s} \leq \limsup _{k \rightarrow \infty} d\left(T x_{n_{k}-1}, T x_{m_{k}}\right) \leq \varepsilon
$$

Consider

$$
d\left(T x_{m_{k}}, T x_{n_{k}}\right) \leq s\left[d\left(T x_{m_{k}}, T x_{m_{k}-1}\right)+d\left(T x_{m_{k}-1}, T x_{n_{k}}\right)\right]
$$

and

$$
d\left(T x_{m_{k}-1}, T x_{n_{k}}\right) \leq s\left[d\left(T x_{m_{k}-1}, T x_{m_{k}}\right)+d\left(T x_{m_{k}}, T x_{n_{k}}\right)\right] .
$$

Using (3.3) and (3.6), we get

$$
\frac{\varepsilon}{s} \leq \limsup _{k \rightarrow \infty} d\left(T x_{m_{k}-1}, T x_{n_{k}}\right) \leq s^{2} \varepsilon
$$

Similarly, we can show that

$$
\frac{\varepsilon}{s} \leq \liminf _{k \rightarrow \infty} d\left(T x_{n_{k}-1}, T x_{m_{k}}\right) \leq \varepsilon
$$

and

$$
\frac{\varepsilon}{s} \leq \liminf _{k \rightarrow \infty} d\left(T x_{m_{k}-1}, T x_{n_{k}}\right) \leq s^{2} \varepsilon .
$$

Since $\frac{s^{2}+1}{s+1} \leq s$ and using (3.1) and (3.7)-(3.10), we have

$$
\begin{aligned}
\psi(s \varepsilon) & \leq \psi\left(s \limsup _{k \rightarrow \infty} d\left(T x_{m_{k}}, T x_{n_{k}}\right)\right) \\
& =\psi\left(s \limsup _{k \rightarrow \infty} d\left(T f x_{m_{k}-1}, T f x_{n_{k}-1}\right)\right) \\
& \leq \frac{\limsup \sup _{k \rightarrow \infty} \psi\left(\frac{d\left(T x_{m_{k}-1}, T x_{n_{k}-1}\right)+d\left(T x_{n_{k}-1}, T f x_{m_{k}-1}\right)}{s+1}\right)}{1+\liminf _{k \rightarrow \infty} \varphi\left(d\left(T x_{m_{k}-1}, T f x_{n_{k}-1}\right), d\left(T x_{n_{k}-1}, T f x_{m_{k}-1}\right)\right)} \\
& \leq \frac{\psi\left(\limsup _{k \rightarrow \infty} \frac{d\left(T x_{m_{k}-1}, T x_{n_{k}}\right)+d\left(T x_{n_{k}-1}, T x_{m_{k}}\right)}{s+1}\right)}{1+\varphi\left(\liminf _{k \rightarrow \infty} d\left(T x_{m_{k}-1}, T x_{n_{k}}\right), \liminf _{k \rightarrow \infty} d\left(T x_{n_{k}-1}, T x_{m_{k}}\right)\right)} \\
& \leq \frac{\psi\left(\frac{s^{2} \varepsilon+\varepsilon}{s+1}\right)}{1+\varphi\left(\liminf _{k \rightarrow \infty} d\left(T x_{m_{k}-1}, T x_{n_{k}}\right), \liminf _{k \rightarrow \infty} d\left(T x_{n_{k}-1}, T x_{m_{k}}\right)\right)} \\
& \leq \frac{\psi(s \varepsilon)}{1+\varphi\left(\liminf _{k \rightarrow \infty} d\left(T x_{m_{k}-1}, T x_{n_{k}}\right), \liminf _{k \rightarrow \infty} d\left(T x_{n_{k}-1}, T x_{m_{k}}\right)\right)} .
\end{aligned}
$$


Hence, we obtain

$$
\varphi\left(\liminf _{k \rightarrow \infty} d\left(T x_{m_{k}-1}, T x_{n_{k}}\right), \liminf _{k \rightarrow \infty} d\left(T x_{n_{k}-1}, T x_{m_{k}}\right)\right) \leq 0 .
$$

By our assumption about $\varphi$, we have

$$
\liminf _{k \rightarrow \infty} d\left(T x_{m_{k}-1}, T x_{n_{k}}\right)=\liminf _{k \rightarrow \infty} d\left(T x_{n_{k}-1}, T x_{m_{k}}\right)=0,
$$

which contradicts (3.9) and (3.10).

Since $(X, d)$ is $b$-complete and $\left\{T x_{n}\right\}=\left\{T f^{n} x_{0}\right\}$ is a $b$-Cauchy sequence, there exists $v \in X$ such that

$$
\lim _{n \rightarrow \infty} \operatorname{Tf}^{n} x_{0}=v
$$

Step III. Now in the last step, first we will prove that $f$ has a unique fixed point by assuming that $T$ is subsequentially convergent.

As $T$ is subsequentially convergent, $\left\{f^{n} x_{0}\right\}$ has a $b$-convergent subsequence. Hence, there exist $u \in X$ and a subsequence $\left\{n_{i}\right\}$ such that

$$
\lim _{i \rightarrow \infty} f^{n_{i}} x_{0}=u
$$

using (3.12) and continuity of $T$, we obtain

$$
\lim _{i \rightarrow \infty} T f^{n_{i}} x_{0}=T u
$$

From (3.11) and (3.13) we have $T u=v$.

From Lemma 2.1 and using (3.1), we have

$$
\begin{aligned}
\psi\left(s \cdot \frac{1}{s} d(T f u, T u)\right) & \leq \psi\left(\limsup _{n \rightarrow \infty} s d\left(T f u, T f^{n+1} x_{0}\right)\right) \\
& =\psi\left(\limsup _{n \rightarrow \infty} s d\left(T f u, T f x_{n}\right)\right) \\
& \leq \frac{\psi\left(\limsup _{n \rightarrow \infty} \frac{d\left(T u, T f x_{n}\right)+d\left(T x_{n}, T f u\right)}{s+1}\right)}{1+\liminf _{n \rightarrow \infty} \varphi\left(d\left(T u, T f x_{n}\right), d\left(T x_{n}, T f u\right)\right)} \\
& \leq \frac{\psi\left(\frac{s d(T u, T u)+s d(T u, T f u)}{s+1}\right)}{1+\varphi\left(\liminf _{n \rightarrow \infty} d\left(T u, T f x_{n}\right), \liminf _{n \rightarrow \infty} d\left(T x_{n}, T f u\right)\right)} \\
& \leq \frac{\psi(d(T u, T f u))}{1+\varphi\left(0, \liminf _{n \rightarrow \infty} d\left(T x_{n}, T f u\right)\right)}
\end{aligned}
$$

Using the properties of $\varphi \in \Phi$, we have $\liminf _{n \rightarrow \infty} d\left(T x_{n}, T f u\right)=0$. By the triangular inequality we get

$$
d(T f u, T u) \leq s\left[d\left(T f u, T x_{n}\right)+d\left(T x_{n}, T u\right)\right]
$$

On letting $n \rightarrow \infty$ in above inequality, we have $d(T f u, T u)=0$. Hence, $T f u=T u$. As $T$ is one-to-one, $f u=u$. Therefore, $f$ has a fixed point. 
Now assume that $w$ is another fixed point of $f$. From inequality (3.1), we have

$$
\begin{aligned}
\psi(s d(T u, T w)) & =\psi(s d(T f u, T f w)) \\
& \leq \frac{\psi\left(\frac{d(T u, T f w)+d(T w, T f u)}{s+1}\right)}{1+\varphi(d(T u, T f w), d(T w, T f u))} \\
& =\frac{\psi\left(\frac{d(T u, T w)+d(T w, T u)}{s+1}\right)}{1+\varphi(d(T u, T w), d(T w, T u))} \\
& \leq \frac{\psi(s d(T u, T w))}{1+\varphi(d(T u, T w), d(T w, T u))}
\end{aligned}
$$

since $\frac{2}{s+1} \leq s$ and $\psi$ is increasing. Hence, $d(T u, T w)=0$. As $T$ is one-to-one, $u=w$. Therefore, $f$ has a unique fixed point.

Finally, if mapping $T$ is sequentially convergent, replacing $\{n\}$ with $\left\{n_{i}\right\}$ we conclude that $\lim _{n \rightarrow \infty} f^{n} x_{0}=u$.

Theorem 3.2 Let $(X, d)$ be a complete b-metric space with parameter $s \geq 1, T, f: X \rightarrow X$ be such that, for some $\psi, \varphi \in \Psi, l>1$ and all $x, y \in X$,

$$
\psi(s d(T f x, T f y)) \leq\left(\psi\left(\frac{d(T x, T f y)+d(T y, T f x)}{s+1}\right)+l\right)^{\frac{1}{1+\varphi(d(T x, T f y), d(T y, T f x))}}-l
$$

and let $T$ be one-to-one and continuous. Then:

(1) For every $x_{0} \in X$ the sequence $\left\{T f^{n} x_{0}\right\}$ is convergent.

(2) If $T$ is subsequentially convergent then $f$ has a unique fixed point.

(3) If $T$ is sequentially convergent then, for each $x_{0} \in X$ the sequence $\left\{f^{n} x_{0}\right\}$ converges to the fixed point of $f$.

Proof Let $x_{0} \in X$ be arbitrary. Consider the sequence $\left\{x_{n}\right\}_{n=0}^{\infty}$ given by $x_{n+1}=f x_{n}=f^{n+1} x_{0}$, for $n \geq 0$.

Step I. First, we will prove that $\lim _{n \rightarrow \infty} d\left(T x_{n}, T x_{n+1}\right)=0$.

Using (3.14), we obtain

$$
\begin{aligned}
\psi & \left(s d\left(T x_{n+1}, T x_{n}\right)\right) \\
& =\psi\left(s d\left(T f x_{n}, T f x_{n-1}\right)\right) \\
& \leq\left(\psi\left(\frac{d\left(T x_{n}, T f x_{n-1}\right)+d\left(T x_{n-1}, T f x_{n}\right)}{s+1}\right)+l\right)^{\frac{1}{1+\varphi\left(d\left(T x_{n}, T f x_{n-1}\right), d\left(T x_{n-1}, T f x_{n}\right)\right)}}-l \\
& =\left(\psi\left(\frac{d\left(T x_{n}, T x_{n}\right)+d\left(T x_{n-1}, T x_{n+1}\right)}{s+1}\right)+l\right)^{\frac{1}{1+\varphi\left(d\left(T x_{n}, T x_{n}\right), d\left(T x_{n-1}, T x_{n+1}\right)\right)}}-l .
\end{aligned}
$$

Since $\varphi$ is nonnegative and $\psi$ is an increasing function and using the triangular inequality we have

$$
\begin{aligned}
\psi\left(s d\left(T x_{n+1}, T x_{n}\right)\right) & \leq \psi\left(\frac{d\left(T x_{n-1}, T x_{n+1}\right)}{s+1}\right) \\
& \leq \psi\left(\frac{s}{s+1}\left(d\left(T x_{n-1}, T x_{n}\right)+d\left(T x_{n}, T x_{n+1}\right)\right)\right)
\end{aligned}
$$


Again, since $\psi$ is increasing, we have

$$
d\left(T x_{n+1}, T x_{n}\right) \leq \frac{1}{s+1}\left(d\left(T x_{n-1}, T x_{n}\right)+d\left(T x_{n}, T x_{n+1}\right)\right)
$$

wherefrom

$$
d\left(T x_{n+1}, T x_{n}\right) \leq \frac{1}{s} d\left(T x_{n}, T x_{n-1}\right) \leq d\left(T x_{n}, T x_{n-1}\right)
$$

Thus, $\left\{d\left(T x_{n+1}, T x_{n}\right)\right\}$ is a decreasing sequence of nonnegative real numbers and hence it is convergent.

Assume that $\lim _{n \rightarrow \infty} d\left(T x_{n+1}, T x_{n}\right)=r \geq 0$. Using similar steps to Theorem 3.1, we obtain

$$
\lim _{n \rightarrow \infty} d\left(T x_{n-1}, T x_{n+1}\right)=s(s+1) r .
$$

From (3.15), we have

$$
\psi\left(s d\left(T x_{n+1}, T x_{n}\right)\right) \leq\left(\psi\left(\frac{0+d\left(T x_{n-1}, T x_{n+1}\right)}{s+1}\right)+l\right)^{\frac{1}{1+\varphi\left(0, d\left(T x_{n-1}, T x_{n+1}\right)\right)}}-l
$$

On letting $n \rightarrow \infty$ and using the continuity of $\psi$ and the properties of $\varphi$ we have

$$
\psi(s r) \leq(\psi(s r)+l)^{\frac{1}{1+\varphi(0, s(s+1) r)}}-l
$$

and consequently, $\psi(s r)=0$. Hence using the properties of $\psi$, we have

$$
r=\lim _{n \rightarrow \infty} d\left(T x_{n}, T x_{n+1}\right)=0
$$

Step II. Now in next step we will show that $\left\{T x_{n}\right\}$ is a $b$-Cauchy sequence.

Suppose that $\left\{T x_{n}\right\}$ is not a $b$-Cauchy sequence. Then there exists $\varepsilon>0$ for which we can find subsequences $\left\{T x_{m_{k}}\right\}$ and $\left\{T x_{n_{k}}\right\}$ of $\left\{T x_{n}\right\}$ with $n_{k}$ being the smallest index for which $n_{k}>m_{k}>k$ such that

$$
d\left(T x_{m_{k}}, T x_{n_{k}}\right) \geq \varepsilon
$$

and

$$
d\left(T x_{m_{k}}, T x_{n_{k}-1}\right)<\varepsilon
$$

From (3.17), (3.18), and using the triangular inequality, we have

$$
\begin{aligned}
\varepsilon & \leq d\left(T x_{m_{k}}, T x_{n_{k}}\right) \leq s\left[d\left(T x_{m_{k}}, T x_{n_{k}-1}\right)+d\left(T x_{n_{k}-1}, T x_{n_{k}}\right)\right] \\
& <s \varepsilon+s d\left(T x_{n_{k}-1}, T x_{n_{k}}\right) .
\end{aligned}
$$

On letting $k \rightarrow \infty$, and using (3.3), we obtain

$$
\varepsilon \leq \limsup _{k \rightarrow \infty} d\left(T x_{m_{k}}, T x_{n_{k}}\right) \leq s \varepsilon
$$


Further, we have

$$
d\left(T x_{m_{k}}, T x_{n_{k}}\right) \leq s\left[d\left(T x_{m_{k}}, T x_{n_{k}-1}\right)+d\left(T x_{n_{k}-1}, T x_{n_{k}}\right)\right] .
$$

Now using (3.16) and (3.18), we get

$$
\frac{\varepsilon}{s} \leq \limsup _{k \rightarrow \infty} d\left(T x_{n_{k}-1}, T x_{m_{k}}\right) \leq \varepsilon
$$

Consider

$$
d\left(T x_{m_{k}}, T x_{n_{k}}\right) \leq s\left[d\left(T x_{m_{k}}, T x_{m_{k}-1}\right)+d\left(T x_{m_{k}-1}, T x_{n_{k}}\right)\right]
$$

and

$$
d\left(T x_{m_{k}-1}, T x_{n_{k}}\right) \leq s\left[d\left(T x_{m_{k}-1}, T x_{m_{k}}\right)+d\left(T x_{m_{k}}, T x_{n_{k}}\right)\right] .
$$

Using (3.16) and (3.19), we get

$$
\frac{\varepsilon}{s} \leq \limsup _{k \rightarrow \infty} d\left(T x_{m_{k}-1}, T x_{n_{k}}\right) \leq s^{2} \varepsilon
$$

Similarly, we can show that

$$
\frac{\varepsilon}{s} \leq \liminf _{k \rightarrow \infty} d\left(T x_{n_{k}-1}, T x_{m_{k}}\right) \leq \varepsilon
$$

and

$$
\frac{\varepsilon}{s} \leq \liminf _{k \rightarrow \infty} d\left(T x_{m_{k}-1}, T x_{n_{k}}\right) \leq s^{2} \varepsilon
$$

Since $\frac{s^{2}+1}{s+1} \leq s$ and using (3.14) and (3.20)-(3.23), we have

$$
\begin{aligned}
& \psi(s \varepsilon) \\
& \leq \psi\left(s \limsup _{k \rightarrow \infty} d\left(T x_{m_{k}}, T x_{n_{k}}\right)\right) \\
& =\psi\left(s \limsup _{k \rightarrow \infty} d\left(T f x_{m_{k}-1}, T f x_{n_{k}-1}\right)\right) \\
& \leq\left(\limsup _{k \rightarrow \infty} \psi\left(\frac{d\left(T x_{m_{k}-1}, T f x_{n_{k}-1}\right)+d\left(T x_{n_{k}-1}, T f x_{m_{k}-1}\right)}{s+1}\right)+l\right)^{\frac{1}{1+\operatorname{limin} f_{k \rightarrow \infty} \varphi\left(d\left(T x_{m_{k}-1}, T f x_{\left.n_{k}-1\right)}\right), d\left(T x_{\left.\left.n_{k}-1, T f x_{m_{k}-1}\right)\right)}\right.\right.}}-l \\
& \leq\left(\psi\left(\limsup _{k \rightarrow \infty} \frac{d\left(T x_{m_{k}-1}, T x_{n_{k}}\right)+d\left(T x_{n_{k}-1}, T x_{m_{k}}\right)}{s+1}\right)+l\right)^{\frac{1}{1+\varphi\left(\liminf _{k \rightarrow \infty} d\left(T x_{m_{k}-1}, T x_{n_{k}}\right), \operatorname{limin} f_{k \rightarrow \infty} d\left(T x_{n_{k}-1}, T x_{m_{k}}\right)\right)}}-l \\
& \leq\left(\psi\left(\frac{s^{2} \varepsilon+\varepsilon}{s+1}\right)+l\right)^{\frac{1}{1+\varphi\left(\liminf _{k \rightarrow \infty} d\left(T x_{m_{k}-1}, T x_{n_{k}}\right), \liminf _{k \rightarrow \infty} d\left(T x_{n_{k}-1}, T x_{m_{k}}\right)\right)}}-l \\
& \leq(\psi(s \varepsilon)+l)^{\frac{1}{1+\varphi\left(\liminf _{k \rightarrow \infty} d\left(T x_{m_{k}-1}, T x_{n_{k}}\right), \lim \operatorname{in}_{k \rightarrow \infty} d\left(T x_{n_{k}-1}, T x_{m_{k}}\right)\right)}}-l .
\end{aligned}
$$


Hence, we have

$$
\varphi\left(\liminf _{k \rightarrow \infty} d\left(T x_{m_{k}-1}, T x_{n_{k}}\right), \liminf _{k \rightarrow \infty} d\left(T x_{n_{k}-1}, T x_{m_{k}}\right)\right) \leq 0 .
$$

By our assumption about $\varphi$, we have

$$
\liminf _{k \rightarrow \infty} d\left(T x_{m_{k}-1}, T x_{n_{k}}\right)=\liminf _{k \rightarrow \infty} d\left(T x_{n_{k}-1}, T x_{m_{k}}\right)=0
$$

which contradicts (3.22) and (3.23).

Since $(X, d)$ is $b$-complete and $\left\{T x_{n}\right\}=\left\{T f^{n} x_{0}\right\}$ is a $b$-Cauchy sequence, there exists $v \in X$ such that

$$
\lim _{n \rightarrow \infty} T f^{n} x_{0}=v
$$

Step III. Now, in the last step, first we will prove that $f$ has a unique fixed point by assuming that $T$ is subsequentially convergent.

As $T$ is subsequentially convergent, $\left\{f^{n} x_{0}\right\}$ has a $b$-convergent subsequence. Hence, there exist $u \in X$ and a subsequence $\left\{n_{i}\right\}$ such that

$$
\lim _{i \rightarrow \infty} f^{n_{i}} x_{0}=u
$$

using (3.25) and continuity of $T$, we obtain

$$
\lim _{i \rightarrow \infty} T f^{n_{i}} x_{0}=T u
$$

From (3.24) and (3.26) we have $T u=v$.

From Lemma 2.1 and using (3.14), we have

$$
\begin{aligned}
& \psi\left(s \cdot \frac{1}{s} d(T f u, T u)\right) \\
& \quad \leq \psi\left(\limsup _{n \rightarrow \infty} s d\left(T f u, T f^{n+1} x_{0}\right)\right) \\
& \quad=\psi\left(\limsup _{n \rightarrow \infty} s d\left(T f u, T f x_{n}\right)\right) \\
& \quad \leq\left(\psi\left(\limsup _{n \rightarrow \infty} \frac{d\left(T u, T f x_{n}\right)+d\left(T x_{n}, T f u\right)}{s+1}\right)+l\right)^{\frac{1}{1+\liminf _{n \rightarrow \infty}\left(d\left(T u, T f x_{n}\right), d\left(T x_{n}, T f u\right)\right)}}-l \\
& \quad \leq\left(\psi\left(\frac{s d(T u, T u)+s d(T u, T f u)}{s+1}\right)+l\right)^{\frac{1}{1+\varphi\left(\liminf \rightarrow \infty d\left(T u, T x_{n}\right), \liminf _{n \rightarrow \infty} d\left(T x_{n}, T f u\right)\right)}}-l \\
& \quad \leq(\psi(d(T u, T f u))+l)^{\frac{1}{1+\varphi\left(0, \lim _{n} \inf _{n \rightarrow \infty} d\left(T x_{n}, T f u\right)\right)}-l .}
\end{aligned}
$$

Using the properties of $\varphi \in \Phi$, we have $\liminf _{n \rightarrow \infty} d\left(T x_{n}, T f u\right)=0$. By the triangular inequality we have

$$
d(T f u, T u) \leq s\left[d\left(T f u, T x_{n}\right)+d\left(T x_{n}, T u\right)\right] .
$$


On letting $n \rightarrow \infty$ in above inequality, we have $d(T f u, T u)=0$. Hence, $T f u=T u$. As $T$ is one-to-one, $f u=u$. Therefore, $f$ has a fixed point.

Now assume that $w$ is another fixed point of $f$. From inequality (3.14), we have

$$
\begin{aligned}
\psi(\operatorname{sd}(T u, T w)) & =\psi(s d(T f u, T f w)) \\
& \leq\left(\psi\left(\frac{d(T u, T f w)+d(T w, T f u)}{s+1}\right)+l\right)^{\frac{1}{1+\varphi(d(T u, T f w), d(T w, T f u))}}-l \\
& =\left(\psi\left(\frac{d(T u, T w)+d(T w, T u)}{s+1}\right)+l\right)^{\frac{1}{1+\varphi(d(T u, T w), d(T w, T u))}}-l \\
& \leq(\psi(s d(T u, T w))+l)^{\frac{1}{1+\varphi(d(T u, T w), d(T w, T u))}}-l
\end{aligned}
$$

since $\frac{2}{s+1} \leq s$ and $\psi$ is increasing. Hence, $d(T u, T w)=0$. As $T$ is one-to-one, $u=w$. Therefore, $f$ has a unique fixed point.

Finally, if $T$ is sequentially convergent, replacing $\{n\}$ with $\left\{n_{i}\right\}$ we conclude that $\lim _{n \rightarrow \infty} f^{n} x_{0}=u$.

If we take $\psi(t)=t$ and $\varphi(t, u)=\frac{s}{(s+1) a}-1, a \in(0,1)$, in Theorem 3.1, we obtain the following result which is an extended Chatterjea fixed point theorem in the setting of $b$-metric spaces.

Corollary 3.1 Let $(X, d)$ be a complete $b$-metric space and $T, f: X \rightarrow X$ be mappings such that $T$ is continuous, one-to-one and subsequentially convergent. If $a \in(0,1)$ and

$$
d(T f x, T f y) \leq \frac{a}{s(s+1)}(d(T x, T f y)+d(T y, T f x))
$$

for all $x, y \in X$, then $f$ has a unique fixed point. Moreover, if $T$ is sequentially convergent, then for every $x_{0} \in X$ the sequence of iterates $f^{n} x_{0}$ converges to this fixed point.

\section{Remark 3.1}

(1) If we take $T x=x$, in Corollary 3.1, then we obtain the result of Jovanovic [16, Corollary $3.8 .3^{\circ}$ ] (the case $g=f$ ), which is Chatterjea's Theorem [2] in the framework of $b$-metric spaces.

(2) By taking $T x=x$ and $\psi(t)=t$ in Theorem 3.1, we obtain an extension of Choudhury's [27] main result to the setup of $b$-metric spaces.

(3) If $s=1$, in Theorem 3.1, we obtain the corresponding result of [30].

Example 3.1 Let $X=\{0\} \cup\{1 / n \mid n \in \mathbb{N}\}$, and let $d(x, y)=(x-y)^{2}$ for $x, y \in X$. Then $d$ is a $b$-metric with the parameter $s=2$ and $(X, d)$ is a complete $b$-metric space. Consider the mappings $f, T: X \rightarrow X$ given by

$$
f(0)=0, \quad f\left(\frac{1}{n}\right)=\frac{1}{n+1}, \quad T(0)=0, \quad T\left(\frac{1}{n}\right)=\frac{1}{n^{n}}, \quad n \in \mathbb{N} .
$$


We will show that the mappings $f, T$ satisfy the conditions of Corollary 3.1 with $\alpha=\frac{2}{9}<$ $\frac{1}{3}=\frac{1}{s+1}$. Indeed, for $m, n \in \mathbb{N}, m>n$, we have

$$
d\left(T f \frac{1}{n}, T f \frac{1}{m}\right)=\left[\frac{1}{(n+1)^{n+1}}-\frac{1}{(m+1)^{m+1}}\right]^{2}<\left[\frac{1}{(n+1)^{n+1}}\right]^{2} .
$$

It is easy to prove that, for $n \in \mathbb{N}$,

$$
\frac{1}{(n+1)^{n+1}}<\frac{1}{3}\left[\frac{1}{n^{n}}-\frac{1}{(n+2)^{n+2}}\right] \text {. }
$$

It follows that

$$
d\left(T f \frac{1}{n}, T f \frac{1}{m}\right)<\frac{1}{9}\left[\frac{1}{n^{n}}-\frac{1}{(n+2)^{n+2}}\right]^{2} .
$$

Now, $m>n$ implies that $m \geq n+1$ and $n+2 \leq m+1$. It follows that $1 /(n+2)^{n+2} \geq 1 /(m+$ $1)^{m+1}$, and hence

$$
\begin{aligned}
d\left(T f \frac{1}{n}, T f \frac{1}{m}\right) & <\frac{1}{9}\left[\frac{1}{n^{n}}-\frac{1}{(m+1)^{m+1}}\right]^{2} \\
& \leq \frac{\alpha}{s}\left[d\left(T \frac{1}{n}, T f \frac{1}{m}\right)+d\left(T \frac{1}{m}, T F \frac{1}{n}\right)\right] .
\end{aligned}
$$

If one of the points is equal to 0 , the proof is even simpler.

By Corollary 3.1, it follows that $f$ has a unique fixed point (which is $u=0$ ).

Theorem 3.3 Let $(X, d)$ be a complete $b$-metric space with the parameter $s \geq 1, T, f: X \rightarrow$ $X$ be such that for some $\psi \in \Psi, \varphi \in \Phi$, and all $x, y \in X$,

$$
\psi(d(T f x, T f y)) \leq \frac{\psi\left(\frac{d(T x, T f x)+d(T y, T f y)}{s+1}\right)}{1+\varphi(d(T x, T f x), d(T y, T f y))},
$$

and let $T$ be one-to-one and continuous. Then:

(1) For every $x_{0} \in X$ the sequence $\left\{T^{n} x_{0}\right\}$ is convergent.

(2) If $T$ is subsequentially convergent then $f$ has a unique fixed point.

(3) If $T$ is sequentially convergent then, for each $x_{0} \in X$ the sequence $\left\{f^{n} x_{0}\right\}$ converges to the fixed point of $f$.

Proof Let $x_{0} \in X$ be arbitrary. Consider the sequence $\left\{x_{n}\right\}_{n=0}^{\infty}$ given by $x_{n+1}=f x_{n}=f^{n+1} x_{0}$, $n \geq 0$.

In the first step, we will prove that $\lim _{n \rightarrow \infty} d\left(T x_{n}, T x_{n+1}\right)=0$.

Using (3.27), we obtain

$$
\begin{aligned}
\psi\left(d\left(T x_{n+1}, T x_{n}\right)\right) & =\psi\left(d\left(T f x_{n}, T f x_{n-1}\right)\right) \leq \frac{\psi\left(\frac{d\left(T x_{n}, T f x_{n}\right)+d\left(T x_{n-1}, T f x_{n-1}\right)}{s+1}\right)}{1+\varphi\left(d\left(T x_{n}, T f x_{n}\right), d\left(T x_{n-1}, T f x_{n-1}\right)\right)} \\
& =\frac{\psi\left(\frac{d\left(T x_{n}, T x_{n+1}\right)+d\left(T x_{n-1}, T x_{n}\right)}{s+1}\right)}{1+\varphi\left(d\left(T x_{n}, T f x_{n}\right), d\left(T x_{n-1}, T f x_{n-1}\right)\right)} .
\end{aligned}
$$


Since $\varphi$ is nonnegative and $\psi$ is increasing, we have

$$
d\left(T x_{n+1}, T x_{n}\right) \leq \frac{d\left(T x_{n}, T x_{n+1}\right)+d\left(T x_{n-1}, T x_{n}\right)}{s+1},
$$

that is,

$$
d\left(T x_{n+1}, T x_{n}\right) \leq \frac{1}{s} d\left(T x_{n}, T x_{n-1}\right) \leq d\left(T x_{n}, T x_{n-1}\right) .
$$

Thus, $\left\{d\left(T x_{n+1}, T x_{n}\right)\right\}$ is a decreasing sequence of nonnegative real numbers and hence it is convergent.

Assume that $\lim _{n \rightarrow \infty} d\left(T x_{n+1}, T x_{n}\right)=r$. On letting $n \rightarrow \infty$ in (3.28) and using the properties of $\psi$ and $\varphi$ we obtain

$$
\psi(r) \leq \frac{\psi\left(\frac{2 r}{s+1}\right)}{1+\varphi(r, r)} \leq \frac{\psi(r)}{1+\varphi(r, r)}
$$

which is possible only if

$$
r=\lim _{n \rightarrow \infty} d\left(T x_{n}, T x_{n+1}\right)=0
$$

Now, we will show that $\left\{T x_{n}\right\}$ is a $b$-Cauchy sequence.

Suppose that this is not true. Then there exists $\varepsilon>0$ for which we can find subsequences $\left\{T x_{m_{k}}\right\}$ and $\left\{T x_{n_{k}}\right\}$ of $\left\{T x_{n}\right\}$ with $n_{k}$ is the smallest index for which $n_{k}>m_{k}>k$ such that $d\left(T x_{m_{k}}, T x_{n_{k}}\right) \geq \varepsilon$. This means that

$$
d\left(T x_{m_{k}}, T x_{n_{k}-1}\right)<\varepsilon
$$

Again, as in Step II of Theorem 3.1 one can prove that

$$
\varepsilon \leq \limsup _{k \rightarrow \infty} d\left(T x_{m_{k}}, T x_{n_{k}}\right) \leq s \varepsilon
$$

Using (3.27) we have

$$
\begin{aligned}
\psi\left(d\left(T x_{m_{k}}, T x_{n_{k}}\right)\right) & =\psi\left(d\left(T f x_{m_{k}-1}, T f x_{n_{k}-1}\right)\right) \\
& \leq \frac{\psi\left(\frac{d\left(T x_{m_{k}-1}, T f x_{m_{k}-1}\right)+d\left(T x_{n_{k}-1}, T f x_{n_{k}-1}\right)}{s+1}\right)}{1+\varphi\left(d\left(T x_{m_{k}-1}, T f x_{m_{k}-1}\right), d\left(T x_{n_{k}-1}, T f x_{n_{k}-1}\right)\right)} \\
& =\frac{\psi\left(\frac{d\left(T x_{m_{k}-1}, T x_{m_{k}}\right)+d\left(T x_{n_{k}-1}, T x_{n_{k}}\right)}{s+1}\right)}{1+\varphi\left(d\left(T x_{m_{k}-1}, T x_{m_{k}}\right), d\left(T x_{n_{k}-1}, T x_{n_{k}}\right)\right)} .
\end{aligned}
$$

Passing to the upper limit as $k \rightarrow \infty$ in the above inequality and using (3.29), we have

$$
\psi(\varepsilon) \leq \frac{\psi(0)}{1+\varphi(0,0)}=0
$$

and so $\psi(\varepsilon)=0$. By our assumptions about $\psi$, we have $\varepsilon=0$, which is a contradiction. Therefore as in Step II of Theorem 3.1, we obtain $\left\{T x_{n}\right\}$ is a $b$-Cauchy sequence. 
Since $(X, d)$ is $b$-complete and $\left\{T x_{n}\right\}=\left\{T f^{n} x_{0}\right\}$ is a $b$-Cauchy sequence, there exists $v \in X$ such that

$$
\lim _{n \rightarrow \infty} T f^{n} x_{0}=v
$$

Now, if $T$ is subsequentially convergent, then $\left\{f^{n} x_{0}\right\}$ has a convergent subsequence. Hence, there exist a point $u \in X$ and a sequence $\left\{n_{i}\right\}$ such that

$$
\lim _{i \rightarrow \infty} f^{n_{i}} x_{0}=u
$$

Using (3.31) and continuity of $T$, we obtain

$$
\lim _{i \rightarrow \infty} T f^{n_{i}} x_{0}=T u
$$

By using (3.30) and (3.32), we obtain $T u=v$.

Using Lemma 2.1 and inequality (3.27), we have

$$
\begin{aligned}
\psi\left(\frac{1}{s} d(T f u, T u)\right) & \leq \psi\left(\limsup _{n \rightarrow \infty} d\left(T f u, T f^{n+1} x_{0}\right)\right) \\
& =\psi\left(\limsup _{n \rightarrow \infty} d\left(T f u, T f x_{n}\right)\right) \\
& \leq \frac{\psi\left(\limsup _{n \rightarrow \infty} \frac{d(T u, T f u)+d\left(T x_{n}, T f x_{n}\right)}{s+1}\right)}{1+\liminf _{n \rightarrow \infty} \varphi\left(d(T u, T f u), d\left(T x_{n}, T f x_{n}\right)\right)} \\
& =\frac{\psi\left(\frac{d(T u, T f u)+0}{s+1}\right)}{1+\varphi(d(T u, T f u), 0)} \\
& \leq \frac{\psi\left(\frac{d(T u, T f u)}{s}\right)}{1+\varphi(d(T u, T f u), 0)}
\end{aligned}
$$

Using the properties of $\varphi \in \Phi, d(T u, T f u)=0$. As $T$ is one-to-one, $f u=u$. Therefore, $f$ has a fixed point.

Uniqueness of the fixed point can be proved similarly to Theorem 3.1.

Finally, if $T$ is sequentially convergent, replacing $\{n\}$ with $\left\{n_{i}\right\}$ we conclude that $\lim _{n \rightarrow \infty} f^{n} x_{0}=u$.

Taking $\psi(t)=t$ and $\varphi(t, u)=\frac{1}{(s+1) a}-1, a \in(0,1)$ in Theorem 3.3, an extended Kannan fixed point theorem in the setting of $b$-metric spaces has been obtained.

Corollary 3.2 Let $(X, d)$ be a complete $b$-metric space with the parameter $s \geq 1, T, f: X \rightarrow$ $X$ be such that for some $a \in\left(0, \frac{1}{s+1}\right)$ and all $x, y \in X$,

$$
d(T f x, T f y) \leq a(d(T x, T f x)+d(T y, T f y))
$$

and let $T$ be one-to-one and continuous. Then:

(1) For every $x_{0} \in X$ the sequence $\left\{T f^{n} x_{0}\right\}$ is convergent.

(2) If $T$ is subsequentially convergent then $f$ has a unique fixed point. 
(3) If $T$ is sequentially convergent then, for each $x_{0} \in X$ the sequence $\left\{f^{n} x_{0}\right\}$ converges to the fixed point of $f$.

\section{Remark 3.2}

(1) If we take $T x=x$, in Corollary 3.2, then we obtain the result of Jovanović et al. [16, Corollary $3.8 .2^{\circ}$ ] (the case $g=f$ ).

(2) If $s=1$, in Corollary 3.2, then we obtain the main result of Moradi (i.e., [29, Theorem 2.1]).

(3) If both of these conditions are fulfilled, we get just the classical result of Kannan [4].

Example 3.2 ([13]) Let $X=\{a, b, c\}$ and $d: X \times X \rightarrow \mathbb{R}$ be defined by $d(x, x)=0$ for $x \in X$, $d(a, b)=d(b, c)=1, d(a, c)=\frac{9}{4}, d(x, y)=d(y, x)$ for $x, y \in X$. It is easy to check that $(X, d)$ is a $b$-metric space (with $s=\frac{9}{8}>1$ ) which is not a metric space. Consider the mapping $f: X \rightarrow X$ given by

$$
f=\left(\begin{array}{lll}
a & b & c \\
a & a & b
\end{array}\right)
$$

We first note that the $b$-metric version of the classical weak Kannan theorem is not satisfied in this example. Indeed, for $x=b, y=c$, we have $d(f x, f y)=d(a, b)=1$ and $d(x, f x)+d(y, f y)=d(b, a)+d(c, b)=2$, hence the inequality

$$
\psi(d(f x, f y)) \leq \psi\left(\frac{d(x, f x)+d(y, f y)}{s+1}\right)-\varphi(d(x, f x), d(y, f y))
$$

cannot hold, whatever $\psi \in \Psi$ and $\varphi \in \Phi$ are chosen.

Take now $T: X \rightarrow X$ defined by

$$
T=\left(\begin{array}{lll}
a & b & c \\
b & c & a
\end{array}\right)
$$

Obviously, all the properties of $T$ given in Corollary 3.2 are fulfilled. We will check that the contractive condition (3.33) holds true if $\alpha$ is chosen such that

$$
\frac{4}{9}<\alpha<\frac{8}{17}=\frac{1}{s+1}
$$

Only the following cases are nontrivial:

$1^{\circ} x=a, y=c$. Then $(3.33)$ reduces to

$$
d(T f a, T f c)=d(b, c)=1=\frac{4}{9} \cdot \frac{9}{4}<\alpha(d(b, b)+d(a, c))=\alpha(d(T a, T f a)+d(T c, T f c))
$$

$2^{\circ} x=b, y=c$. Then $(3.33)$ reduces to

$$
d(T f b, T f c)=d(b, c)=1<\frac{4}{9} \cdot \frac{13}{4}<\alpha(d(c, b)+d(a, c))=\alpha(d(T b, T f b)+d(T c, T f c))
$$

All the conditions of Corollary 3.2 are satisfied and $f$ has a unique fixed point $(u=a)$. 


\section{Competing interests}

The authors declare that they have no competing interests.

\section{Authors' contributions}

All authors read and approved the final manuscript.

\section{Author details}

${ }^{1}$ Department of Mathematics, Karaj Branch, Islamic Azad University, Karaj, Iran. ${ }^{2}$ Department of Mathematics, Khalsa College of Engineering \& Technology, Punjab Technical University, Amritsar, Punjab 143001, India. ${ }^{3}$ Department of Mathematics and Informatics, University Politehnica of Bucharest, Bucharest, 060042, Romania.

\section{Acknowledgements}

The work has been funded by the Sectoral Operational Programme Human Resources Development 2007-2013 of the Ministry of European Funds through the Financial Agreement POSDRU/159/1.5/S/132395.

\section{Received: 29 July 2014 Accepted: 16 October 2014 Published: 31 Oct 2014}

\section{References}

1. Banach, S: Sur les operateurs dans les ensembles abstraits et leur application aux équations intégrales. Fundam. Math. 3, 133-181 (1922)

2. Chatterjea, SK: Fixed point theorems. C. R. Acad. Bulgare Sci. 25, 727-730 (1972)

3. Haghi, RH, Postolache, M, Rezapour, S: On T-stability of the Picard iteration for generalized $\phi$-contraction mappings. Abstr. Appl. Anal. 2012, Article ID 658971 (2012)

4. Kannan, R: Some results on fixed points. Bull. Calcutta Math. Soc. 60, 71-76 (1968)

5. Olatinwo, MO, Postolache, M: Stability results for Jungck-type iterative processes in convex metric spaces. Appl. Math. Comput. 218(12), 6727-6732 (2012)

6. Chandok, S, Narang, TD, Taoudi, MA: Some common fixed point results in partially ordered metric spaces for generalized rational type contraction mappings. Vietnam J. Math. 41(3), 323-331 (2013)

7. Filipović, M, Paunović, L, Radenović, S, Rajović, M: Remarks on cone metric spaces and fixed point theorems of T-Kannan and T-Chatterjea contractive mappings. Math. Comput. Model. 54, 1467-1472 (2011)

8. Morales, JR, Rojas, E: Cone metric spaces and fixed point theorems of T-Kannan contractive mappings. Int. J. Math. Anal. 4(4), 175-184 (2010)

9. Chandok, S, Mustafa, Z, Postolache, M: Coupled common fixed point theorems for mixed $g$-monotone mappings in partially ordered G-metric spaces. Sci. Bull. 'Politeh.' Univ. Buchar., Ser. A, Appl. Math. Phys. 75(4), 13-26 (2013)

10. Shatanawi, W, Postolache, M: Some fixed point results for a G-weak contraction in G-metric spaces. Abstr. Appl. Anal. 2012, Article ID 815870 (2012)

11. Aghajani, A, Abbas, M, Roshan, JR: Common fixed point of generalized weak contractive mappings in partially ordered $b$-metric spaces. Math. Slovaca (to appear)

12. Czerwik, S: Contraction mappings in b-metric spaces. Acta Math. Inform. Univ. Ostrav. 1, 5-11 (1993)

13. Mustafa, Z, Roshan, JR, Parvaneh, V, Kadelburg, Z: Fixed point theorems for weakly T-Chatterjea and weakly $T$-Kannan contractions in b-metric spaces. J. Inequal. Appl. 2014, Article ID 46 (2014)

14. Roshan, JR, Shobkolaei, N, Sedghi, S, Abbas, M: Common fixed point of four maps in b-metric spaces. Hacet. J. Math. Stat. (to appear)

15. Shatanawi, W, Pitea, A, Lazovic, R: Contraction conditions using comparison functions on $b$-metric spaces. Fixed Point Theory Appl. 2014, Article ID 135 (2014)

16. Jovanović, M, Kadelburg, Z, Radenović, S: Common fixed point results in metric-type spaces. Fixed Point Theory Appl. 2010, Article ID 978121 (2010). doi:10.1155/2010/978121

17. Khan, MS, Swaleh, M, Sessa, S: Fixed point theorems by altering distances between the points. Bull. Aust. Math. Soc. 30, 1-9 (1984)

18. Miandaragh, MA, Postolache, M, Rezapour, S: Some approximate fixed point results for generalized alpha-contractive mappings. Sci. Bull. 'Politeh.' Univ. Buchar., Ser. A, Appl. Math. Phys. 75(2), 3-10 (2013)

19. Miandaragh, MA, Postolache, M, Rezapour, S: Approximate fixed points of generalized convex contractions. Fixed Point Theory Appl. 2013, Article ID 255 (2013)

20. Shatanawi, W, Postolache, M: Common fixed point theorems for dominating and weak annihilator mappings in ordered metric spaces. Fixed Point Theory Appl. 2013, Article ID 271 (2013)

21. Hussain, N, Đorić, D, Kadelburg, Z, Radenović, S: Suzuki-type fixed point results in metric type spaces. Fixed Point Theory Appl. 2012, Article ID 126 (2012)

22. Chandok, S: Some common fixed point theorems for generalized $f$-weakly contractive mappings. J. Appl. Math. Inform. 29, 257-265 (2011)

23. Chandok, S: Some common fixed point theorems for generalized nonlinear contractive mappings. Comput. Math. Appl. 62, 3692-3699 (2011)

24. Chandok, S: Common fixed points, invariant approximation and generalized weak contractions. Int. J. Math. Math. Sci. 2012, Article ID 102980 (2012)

25. Chandok, S: Common fixed points for generalized nonlinear contractive mappings in metric spaces. Mat. Vesn. 65, 29-34 (2013)

26. Chandok, S, Postolache, M: Fixed point theorem for weakly Chatterjea type cyclic contractions. Fixed Point Theory Appl. 2013, Article ID 28 (2013)

27. Choudhury, BS: Unique fixed point theorem for weak C-contractive mappings. Kathmandu Univ. J. Sci. Eng. Technol. 5(1), 6-13 (2009)

28. Harjani, J, Lopez, B, Sadarangani, K: Fixed point theorems for weakly C-contractive mappings in ordered metric spaces. Comput. Math. Appl. 61, 790-796 (2011)

29. Moradi, S: Kannan fixed-point theorem on complete metric spaces and on generalized metric spaces depended on another function. arXiv:0903.1577v1 [math.FA] 
30. Razani, A, Parvaneh, V: Some fixed point theorems for weakly $T$-Chatterjea and weakly $T$-Kannan-contractive mappings in complete metric spaces. Russ. Math. (Izv. VUZ) 57(3), 38-45 (2013)

31. Shatanawi, W: Fixed point theorems for nonlinear weakly C-contractive mappings in metric spaces. Math. Comput. Model. 54, 2816-2826 (2011)

32. Beiranvand, A, Moradi, S, Omid, M, Pazandeh, H: Two fixed point theorems for special mapping. arXiv:0903.1504v1 [math.FA]

10.1186/1029-242X-2014-429

Cite this article as: Ansari et al.: Fixed point theorems on $b$-metric spaces for weak contractions with auxiliary functions. Journal of Inequalities and Applications 2014, 2014:429

Submit your manuscript to a SpringerOpen ${ }^{\circ}$ journal and benefit from:

- Convenient online submission

Rigorous peer review

- Immediate publication on acceptance

Open access: articles freely available online

- High visibility within the field

- Retaining the copyright to your article

Submit your next manuscript at $>$ springeropen.com 